\title{
COMUNICAÇÃo
}

\section{Programa de Requalificação do Centro de Memória Brenno Renato: desafios e perspectivas Qualification Program of the Center of Memory Brenno Renato:
challanges and perspectives}

\author{
Silvana Cançado Trindade* \\ Rafael Leite ${ }^{* *}$ \\ Estevão Fernandes ${ }^{* * *}$
}

O Programa de Requalificação do Centro de Memória Brenno Renato (CMBR), que faz parte da Gerência de Cultura do Minas Tênis Clube (MTC) é constituído por projetos que abrangem ações sequenciais e interdependentes, concebidas com vista a dotar o espaço de um padrão exemplar de funcionamento. Criado em 1997 e remodelado em 2007, o Centro de Memória do Minas vive, hoje, um momento especial em razão da redinamização por que passa o setor cultural do Clube. Junto a um teatro, a um cinema e a uma galeria de arte, o CMBR integrará a estrutura do Centro de Cultura do Minas Tênis Clube, essa integração já está em processo de implantação. Esse é, sem dúvida, um empreendimento que acena para uma nova fase na história do MTC, na qual os horizontes de atuação do Clube se ampliam e as possibilidades de diálogo com a cidade se renovam.

Por conseguinte, repensar a missão do CMBR como espaço, em sua essência, destinado à preservação e difusão da história do Minas, significa conceber novos projetos e novas ações focados em áreas técnicas distintas, objetivando promover o aprimoramento e a oferta de serviços de qualidade, que sejam compatíveis com a nova estrutura de funcionamento da área cultural do Minas.

Esse é o cerne do Programa em pauta. Elaborado em meados de 2011 e apresentado, ainda como uma proposta, durante o $1^{\circ}$ Seminário Internacional de

\footnotetext{
* Graduada em História pela Universidade Federal de Minas Gerais (UFMG), especialista em Cultura e Arte Mineira pela Universidade do Estado de Minas Gerais (UEMG). Coordenadora do Centro de Memória Brenno Renato da Gerência de Cultura do Minas Tênis Clube.

** Graduado em História pela Universidade Federal de Minas Gerais (UFMG), analista do Centro de Memória Brenno Renato (CMBR).

*** Graduado em História pela Universidade Federal de Minas Gerais (UFMG), auxiliar técnico do Centro de Memória Brenno Renato (CMBR).
} 
Memória do Esporte realizado em São Paulo, em outubro do mesmo ano, o Programa de Requalificação do Centro de Memória Brenno Renato cumpre, hoje, as primeiras ações, com a perspectiva de se concluir em 2014.

$\mathrm{Na}$ apresentação do Programa, importa, primeiramente, entender o processo de implantação do CMBR, sua presença na estrutura organizacional do Clube, a constituição de seu acervo e sua atuação ao longo dos anos, informações essas que foram fundamentais para a elaboração do Programa e de projetos constitutivos.

O delineamento do setor cultural no Minas iniciou-se com a criação do Departamento Musical em 1947, responsável por espetáculos com orquestras, audições de piano e de outros instrumentos, com grande repercussão na imprensa da cidade. Em 1962, o setor revigorou-se com a institucionalização do Departamento Cultural e Artístico, que assumiu a responsabilidade de promover exposições de arte e lançamentos de livros, além de apresentações de óperas. Atribuições educativas, como cursos de teatro, cinema, literatura, dança e canto, foram incorporadas em 1987 ao Departamento, designado Assessoria Cultural a partir daquele ano.

Em 1997, foi criada a Sala Brenno Renato ${ }^{1}$, destinada a reunir e guardar os acervos históricos do Minas e que contava com uma coleção inicial de 25 mil fotos e 2 mil troféus. A partir de 2002, a área cultural do Clube, reorganizada na forma de Diretoria de Cultura, passou a considerar que oferecer boas condições de acesso aos acervos históricos era também atividade sob sua responsabilidade. As novas atribuições assumidas motivaram a modernização da Sala, que, em 2007, foi reconcebida nos moldes de um centro de memória, com a finalidade de proceder ao recolhimento, ao tratamento e à divulgação dos acervos referentes à história do MTC.

\section{Diagnóstico do CMBR}

Um diagnóstico de identificação dos pontos positivos e negativos do funcionamento do CMBR foi o ponto de partida para a elaboração do Programa de Requalificação. A análise do diagnóstico deixou claro que o desempenho do Centro de Memória, ao longo dos anos, era bastante tímido. Menos de 5\% das demandas são de procedência externa, sendo mais de $90 \%$ dos pedidos encaminhados pelas gerências e pelos departamentos do Clube ou são solicitações de associados, atletas, ex-atletas e

\footnotetext{
${ }^{1}$ Brenno Renato Martins da Costa é considerado "torcedor símbolo" do MTC. Esteve presente no Minas de 1940 a 1990, ano de seu falecimento. Como diretor de basquete e vôlei, iniciou o trabalho de organização da memória do Clube, colecionando fotos, artigos de jornais, troféus e medalhas.
} 
familiares. Ou seja, os acervos do CMBR (fotográfico, de objetos, fílmico e arquivístico) ainda não foram explorados pelo público externo ou não são reconhecidos como fontes documentais e suportes de informação histórica para a elaboração de estudos e pesquisas, de diferentes níveis de aprofundamento, sobre a história de Belo Horizonte, do Minas Tênis Clube ou da relação deste com o projeto de modernização da cidade de fins dos anos de 1930 e 1940, ou ainda como oportunidade de fruição ou leitura despretensiosa.

São, aproximadamente, 40 mil fotos, datadas de meados dos anos de 1930 até os dias de hoje; mais de 3.000 premiações, entre troféus, taças, placas, medalhas comemorativas de vitórias em campeonatos e disputas; indumentárias esportivas de diversas épocas; mobiliário dos anos de 1940, contemporâneo à inauguração da sede social do Minas, localizada na rua da Bahia; conjunto de filmes em DVD, com registros de eventos esportivos, culturais e de lazer; documentação arquivística, a exemplo do relatório de 1937 que norteou a organização do Clube; os primeiros relatórios produzidos pelos departamentos esportivos, atas de reuniões, relatórios de atividades, balancetes e estatutos, enfim acervos de diferentes tipologias, que se encontram inventariados apenas parcialmente e, portanto, ainda por serem descobertos.

De outra parte, o diagnóstico também identificou dificuldades referentes à guarda, ao acondicionamento e à conservação dos acervos, entre as quais chama particular atenção o número significativo de premiações recebidas pelo Minas. Não se pode esquecer que são nove modalidades de esporte e cinquenta e sete categorias (de base e profissional), o que implica incontáveis campeonatos realizados por ano, resultando na transferência anual para o Centro de Memória de cerca de 40 premiações. É evidente que o acúmulo crescente das taças, das medalhas e dos troféus recebidos demanda a ampliação (na mesma proporção) do espaço físico para o acondicionamento e a realização dos serviços de tratamento e higienização. Portanto, a revisão dos critérios de transferência e incorporação de premiações ao acervo do CMBR é urgente. Com esse fim, serão realizadas visitas técnicas aos centros de memórias de instituições afins ao MTC, a exemplo do Centro Pró-memória Hans Nobiling, do Esporte Clube Pinheiros de São Paulo, que também se dedica à prática do esporte competitivo. Levando-se em conta a experiência dessas instituições, deverão ser definidos novos critérios para a seleção e para o recolhimento das premiações.

O acesso público aos acervos e a disponibilização de informações são também aspectos que se destacam no processo de requalificação funcional do CMBR, por 
exigirem modernização e substituição de sistemas e equipamentos. Os recursos tecnológicos adotados tem-se mostrado insuficientes, seja para atender à demanda dos usuários habituais do Centro ou mesmo para despertar interesse de novos públicos, fato que se agrava considerando-se a carência de espaço expositivo. Nessa perspectiva, vale lembrar que as ações de preservação e conservação somente farão sentido, se forem entendidas como estratégias que promoverão o acesso e a difusão dos acervos para o público em geral.

\section{O Programa de Requalificação: projetos e ações prioritárias}

Os aspectos abordados no diagnóstico, sumariamente descritos acima, nortearam a elaboração do Programa de Requalificação, consubstanciado em projetos considerados estruturantes e que espelham as três vertentes de preservação, pesquisa e comunicação museológica - pilares para o bom funcionamento de museus e espaços museológicos afins. Os projetos são: 1. Projeto de Processamento Técnico do Acervo de Objetos/Premiações que inclui o inventário e as ações de conservação preventiva e higienização; 2. Projeto de Conservação, Higienização, Digitalização e Descrição do Acervo Arquivístico (datado de 1935 a 1984); 3. Projeto de Modernização do Banco de Dados dos Acervos; e 4. Projeto da Exposição de longa duração.

Iniciados em janeiro de 2012, com a supervisão do CMBR, esses projetos encontram-se em andamento, realizados, concomitantemente, por profissionais da área de restauração, arquivo, museu e informática, contratados pelo MTC. No presente momento, realizam-se serviços de conservação e o trabalho de inventário descritivo e fotográfico de 3.000 premiações, além da conservação, digitalização e o inventário descritivo da documentação arquivística. $\mathrm{O}$ trabalho de conservação é realizado em dois ateliês instalados provisoriamente dentro do próprio clube. Além de ser alternativa financeiramente menos dispendiosa e mais segura por se evitar a saída dos acervos das dependências do Clube, o ateliê de conservação em funcionamento - fato inédito no Minas - tem repercutido e sensibilizado sócios e colaboradores, ganhando, ainda que informalmente, a dimensão de ação educativa patrimonial, o que contribui para a instalação e consolidação da cultura preservacionista no Clube.

Cumpre lembrar, no que se refere ao inventário, que esse é um projeto de absoluta relevância por ser instrumento de pesquisa e preservação por meio do qual se legitimará o valor cultural dos objetos em processo de inventariação. Além disso, o 
inventário norteará a política de acervos do Centro de Memória, no sentido de apontar as lacunas ou saturação de informações, sinalizando as futuras iniciativas para incorporações e descartes de acervos. Tendo em vista que as diferentes categorias de acervos - objeto, fotográfico, arquivístico e fílmico - implicam metodologias de inventários distintas, foram criadas planilhas específicas para o registro das informações e elaborados os respectivos manuais de preenchimento .

Espelhando as quatro funções finalísticas do Minas - esporte, lazer, educação e cultura - bem como a estrutura de funcionamento, o arranjo das coleções do CMBR foi construído, buscando evidenciar a organicidade do acervo e viabilizar possibilidades de diálogo e o cruzamento de informações. Os acervos foram organizados em 29 coleções, que perpassam igualmente as tipologias diferentes de acervos - objetos, fotográfico e filmes - algumas das quais divididas em sub-coleções. São elas: natação, vólei masculino e feminino, tênis, basquete, futsal, judô, ginástica de trampolim e artística, tiro ao alvo, squash, eventos sociais e culturais, lazer, educação, arquitetura e equipamentos do Minas 1 e 2 - Náutico e Country -, medicina esportiva, funcionários, sócios, diretoria, voluntariado, biblioteca Caio Martins, publicidade, torneios e mérito cultural, esportivo e social.

Para fortalecer o inventário como instrumento de pesquisa a ser disponibilizado a médio prazo, indistintamente, para o público interno e externo e também para imprimir versatilidade e eficiência às consultas, o banco de dados do centro de memória passou por processo de modernização no que se refere à engenharia de funcionamento, prevendo-se também a modernização de seu projeto gráfico, numa linguagem visual arrojada que atraia novos usuários.

$\mathrm{Na}$ extensa cadeia de procedimentos indispensáveis de requalificação insere-se o Projeto da Exposição de Longa Duração do CMBR, prevista para se inaugurar em 2013, numa sala do Centro de Cultura do Minas Tênis Clube, especialmente, projetada para esse fim. A exposição deverá contar a história do Minas, percorrendo o período que vai desde a sua criação e inauguração em meados da década de 1930 até os dias de hoje. Fundamentalmente, o propósito é de se evidenciar não somente a história do Clube propriamente dita, mas, sobretudo, desvelar intersecções desta com a história de Belo Horizonte e também a atuação do Minas como foco de irradiação da prática esportiva em todo Estado e como exemplar de arquitetura e engenharia que inspirou a construção de praças de esporte em municípios mineiros nas décadas de 1930 e 1940, a exemplo de Pará de Minas, Varginha, Uberlândia e Ubá, que receberam a designação "Praça de 
Esporte Minas Gerais”, a mesma com que o Minas era conhecido.

A exposição será também vetor na construção do projeto de ação educativa e cultural, que deverá atender a interesses de públicos de diferentes faixas etárias. As ações educativas terão o formato de oficinas cujos temas serão elencados pela própria exposição. No escopo das ações culturais, insere-se a realização de exposições de curta duração e o ciclo de palestras com temas relacionados a Belo Horizonte, ao Minas e ao esporte em geral.

\section{Considerações finais}

Com objetivos específicos e metodologias de trabalho próprias - alguns em desenvolvimento e outros em elaboração, previstos para se realizarem nos próximos anos - os projetos e as ações que conformam o Programa de Requalificação do CMBR tem em comum o mesmo fim que é propiciar um novo olhar sobre a história do Minas Tênis Clube, que, de forma abrangente, se estenda por Belo Horizonte, buscando reconstruir a relação estabelecida entre a cidade e o Clube em fins dos anos de 1930.

Há de se entender que, decorrente da implantação do Centro de Cultura do MTC, cujo acesso será aberto a toda população, o CMBR tem hoje o desafio de se rever como equipamento cultural para o qual convergirão novos públicos. Para responder às novas demandas à altura das expectativas, o CMBR redefine sua missão e aprimora seu funcionamento por meio da oferta de serviços de qualidade.

Seja como imponente marco arquitetônico que desponta na paisagem urbana da cidade ou como referência de lazer e de ocorrência de práticas culturais múltiplas, o Minas Tênis Clube deverá se inserir na história de Belo Horizonte, por meio de duas abordagens que serão materializadas nos projetos e nas ações do Centro de Memória.

A primeira abordagem se refere à história propriamente dita do Clube, que visa reforçar, permanentemente, os vínculos de pertencimento de um grupo social à instituição. Mais abrangente, a segunda abordagem tem o propósito de contextualizar historicamente a criação do MTC, como expressão do processo de modernização de Belo Horizonte, promovido pelos prefeitos Otacílio Negrão de Lima (1935 a 1938), José Oswaldo de Araújo (1938 a 1940) e Juscelino Kubistchek (1940 a 1945) e que culminou com a construção do Conjunto Arquitetônico e Paisagístico da Pampulha, a vinda para Minas Gerais do artista Alberto da Veiga Guignard, a criação da Escola Guignard, a inauguração do Museu Histórico Abílio Barreto, a realização de sucessivos 
salões e exposições de arte, acontecimentos estes que imprimiram à cidade um ar cosmopolita e de progresso, entre os quais o Minas é exemplo.

O Centro de Memória Brenno Renato deverá, portanto, posicionar-se como agente prestador de serviços demandados pela população em geral, indistintamente, comunidade interna e externa ao Clube, e também como lugar privilegiado de interseção entre o passado e o futuro, tomando para si a função de um mirante que se volta para a instituição e, ao mesmo tempo, para cidade.

\section{Referências}

MINAS TÊNIS CLUBE. Tradição e modernidade. Belo Horizonte: MTC, 1999.

RODRIGUES, Marilita A. Arantes. Constituição do sentido de Esporte: pelas trilhas históricas do Minas Tênis Clube. 1996. Dissertação (Mestrado em Educação Física) Universidade Federal de Minas Gerais, Belo Horizonte.

SECRETARIA DE ESTADO DE CULTURA. Caderno de Diretrizes Museológicas. Superintendência de Museus, 2002. 